\title{
Intracardiac Phonocardiography
}

Second Report

By

\author{
Kunio Yamakawa, Yasuo Shionoya, Toichi Nagai, \\ (山川邦夫) (暨谷康雄) (永井東一)
}

Kazuo Kitamura, Satoshi Ohta and Takaya Yamamoto

(北村和夫) (太界怜) (山本田力也)

First Medical Clinic, Tokyo University, School of Medicine.

Director: Prof, S. Tasaka

(Received for publication, July 14, 1953)

In the previous report ${ }^{1}$, the authors described the method of intracardiac phonocardiography, on which several improvements were later made in order to assure more precise analyses and these are described in the present paper.

A fine, shielded wire was used for the lead wire between the metal stick at the tip of the catheter and the grid of the oscillator circuit. This limited the conversion of frequency by high frequency to the tip of the catheter. By this means, it became possible to record more selectively the vibration in the desired portion of the heart cavity.

By a similar method, Tomomatsu and Takasaki ${ }^{2)}$," obtained the slow vibration from the right auricle. However, they did not use a shielded wire for the lead and their apparatus is said to be entirely insensible to sound waves when the catheter left in the air.

The apparatus used in the present experiment, as long as the tuning was perfect, is extremely sensitive to sound waves when the catheter is left in the air, showing that the catheter could act as an extremely small microphone which could not have been manufactured to date.

It follows, therefore, that the apparatus and the object of research by Tomomatsu and Takasaki are a great deal different from those of the present study.

\section{EXPERIMENTAL}

Using over 20 adult dogs, the catheter was introduced into right heart by incision through the cervical vein, or to the left heart through the carotid artery. The position of the tip of the catheter was confirmed by the fluoroscope.

Venous catheterisation was also carried out on three human beings 


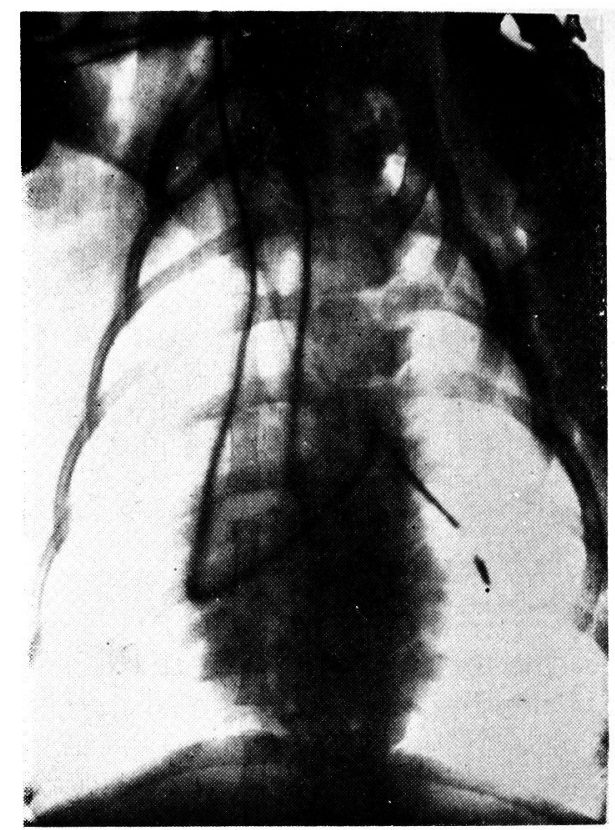

Fig. 1. - One catheter in left descending limb of pulmonary artery, and another in left ventricle.

with this catheter microphone, in one of which the catheter reached the pulmonary artery and heart sounds at various parts in the heart was recorded on the tape-recorder.

In continuation of the previous report, results obtained with dogs are described in the following.

1. Fig. $2 \mathrm{a}$ is the recording obtained from the descending limb of the left pulmonary artery, and $b$, that from the common pulmonary artery. Both are high-pitched murmur of holosystole and the contour is oval or ellipsoidal, similar to the murmur of semilunar valve stenosis. The time elapsed from $Q$ in the Ecg. to the beginning of murmur is 0.03 seconds shorter in $b$ than in a. This means that the record obtained is that of a whirlpool of blood flow at the tip of the catheter.

2. Fig. 3a shows the recording obtained by contacting the tip of the catheter on the inner wall of the left ventricle by its introduction through the carotid artery, and b, the recording from the chest wall made at the same time. The former recording shows the distinct auricular sound. The first sound complex of which is very similar to the first sound from the chest wall.

3. Figs. 4, a, b and $\mathrm{c}$ are the recordings from various points in left ventricle of the same $\operatorname{dog}$ as above. Presystolic ellipsoidal murmur is 

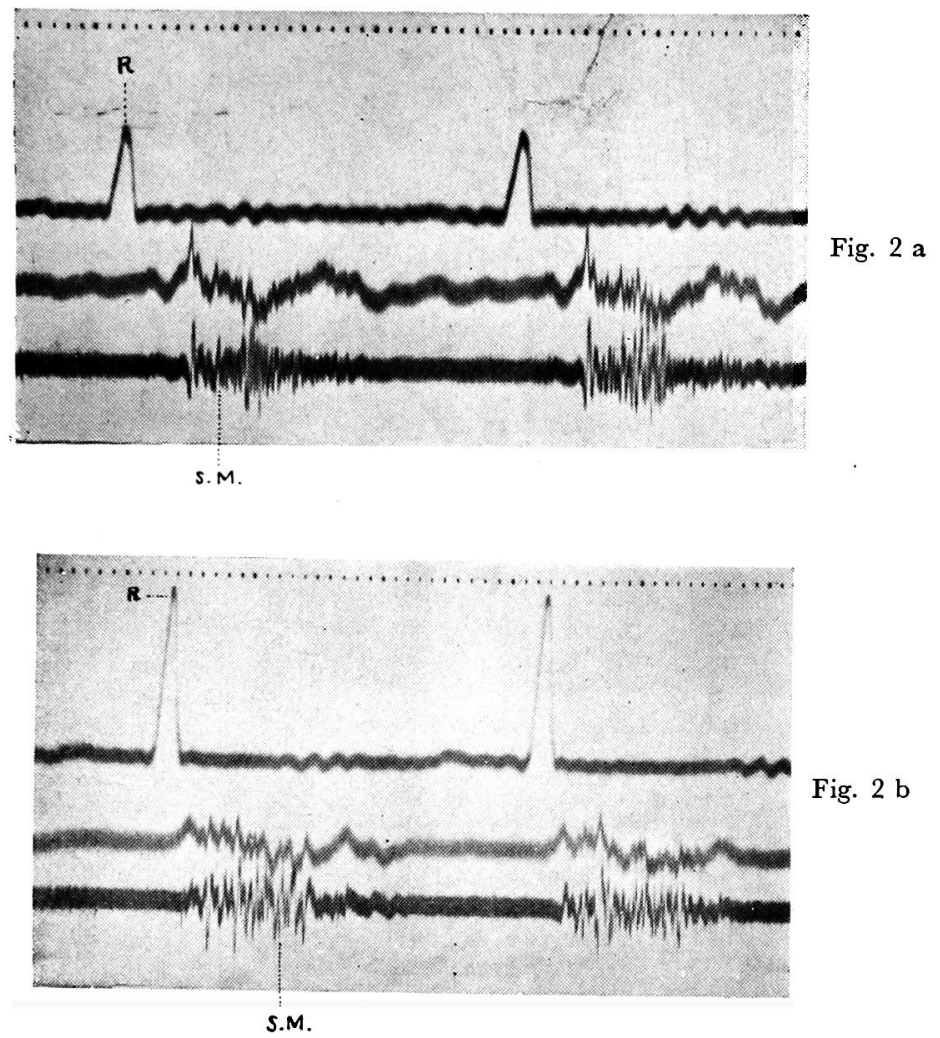

Fig. 2 b

Fig. 2. Tracings from pulmonary artery.

especially well shown in Fig. 4a. It is not clear whether this resulted from a temporary mitral stenosis caused by the tip of the catheter having pushed the mitral valve, or whether such a whirlpool of blood flow exists in the left ventricle. This presystolic murmur cannot be observed from chest wall at the same time.

4. Fig. 5 is the recording obtained from a point near the aortic valve in the left ventricle. It shows the auricular sound and a murmur of small amplitude that follows it. The first sound is either prolonged or split, and follows a rough systolic murmur. The second sound is in some cases split and a large third sound follows.

5. Fig. $6 a$ and b. When the tip of the catheter is placed in the blood stream in aortic arch, holosystolic, high-pitched murmur is present, as in the case of pulmonary artery, and it is very similar to the auscultatory findings of aortic stenosis. When the tip of the catheter is contacted with aortic wall, the first and second sounds become more clear, as can be seen from Fig. 6b. In this instance, this strong systolic murmur can- 

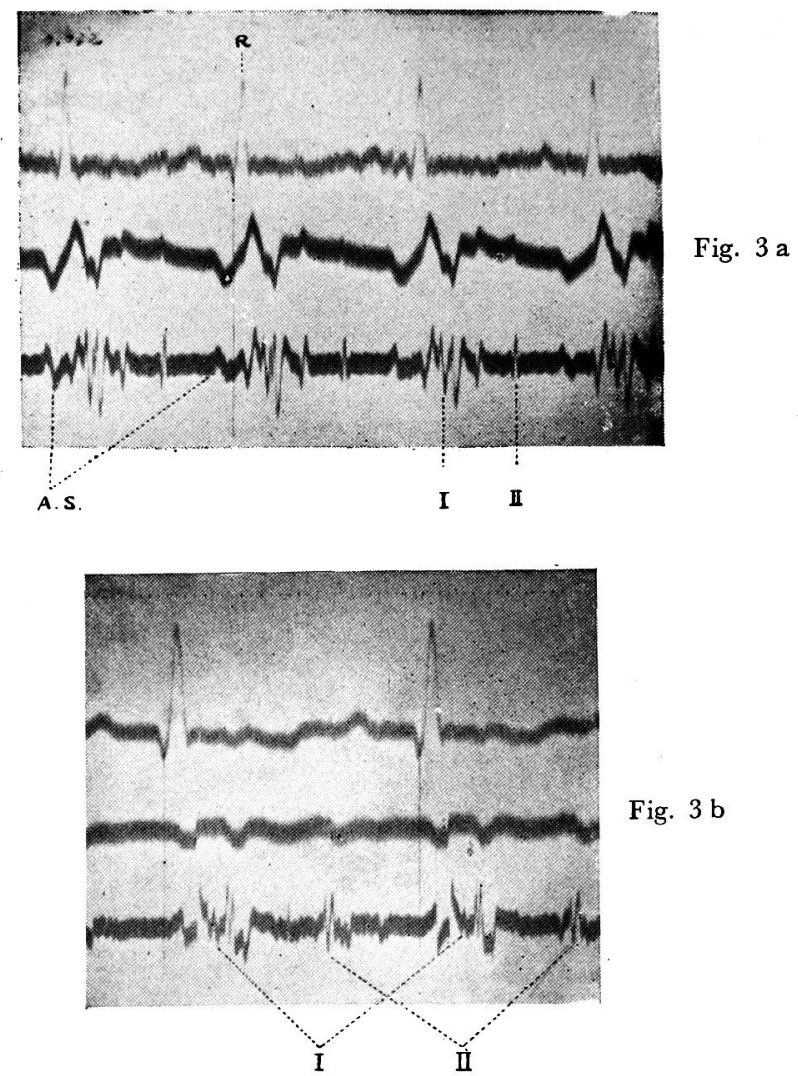

Fig. $3 \mathrm{~b}$

Fig. 3. Tracings from left ventricle and chest wall.

not be seen in the cardiograph taken from chest wall at the same time (Fig. 6c). The whining of a dog is extremely damaging to the recording from chest wall, but it does not give so much effect on the cardiograph taken from the left ventricle or aorta. These results show that myocardium and aortic wall exert an extreme damping effect on vibration, especially of higher frequency.

SUMMARY

1. Intracardiac heart sounds of dogs and men were recorded on a tape-recorder and these recordings were heard by many cardiologists at the Annual Meeting of the Society of Angiocardiology of Japan in 1953.

2. The data obtained to date by the present authors indicate that there exists a certain amount of blood whirlpool inside the heart cavities and arteries. Although this whirlpool is mostly in audible range, the 

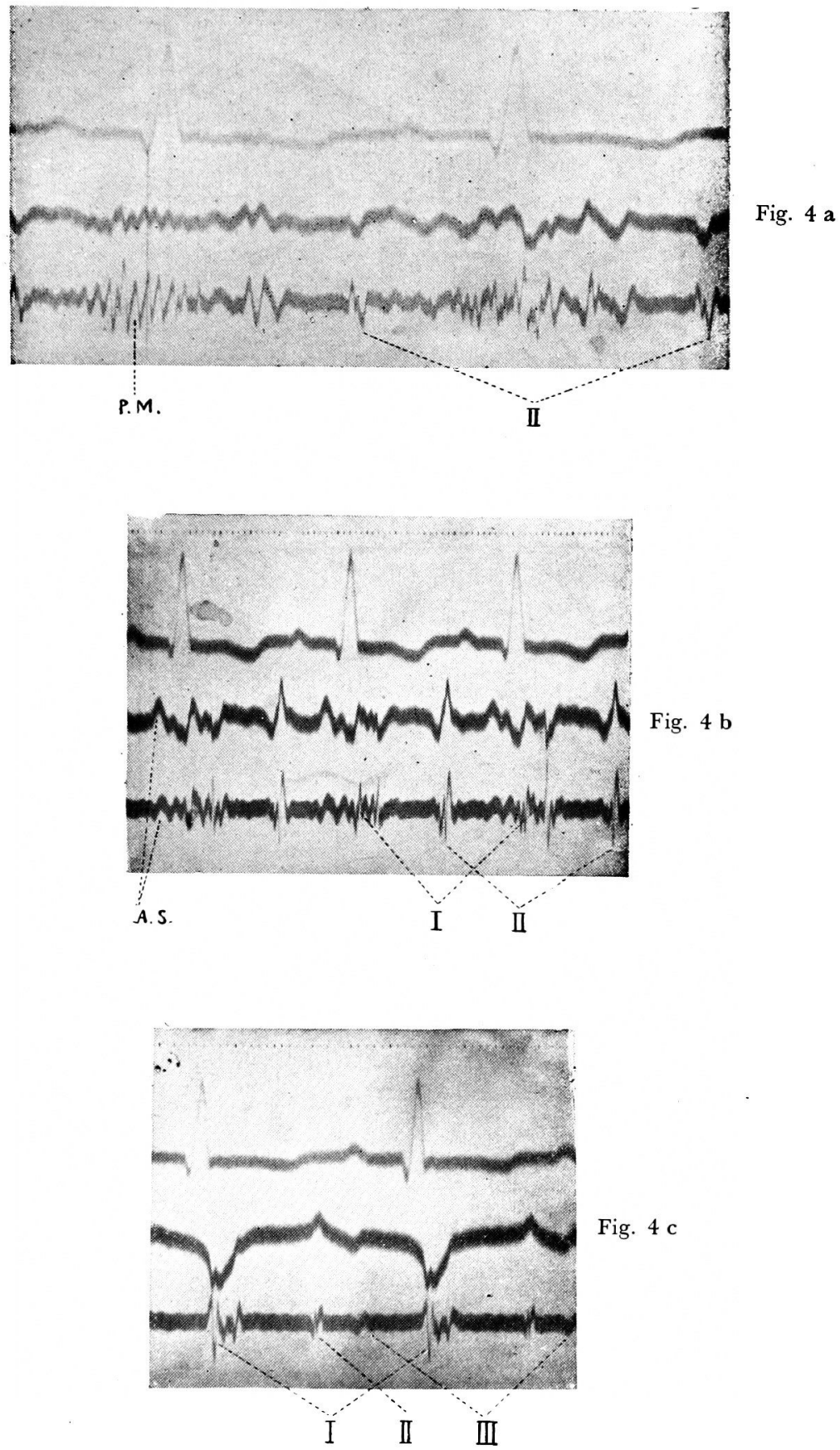

Fig. $4 \mathrm{c}$

Fig. 4. Tracings from various points of left ventricle. 


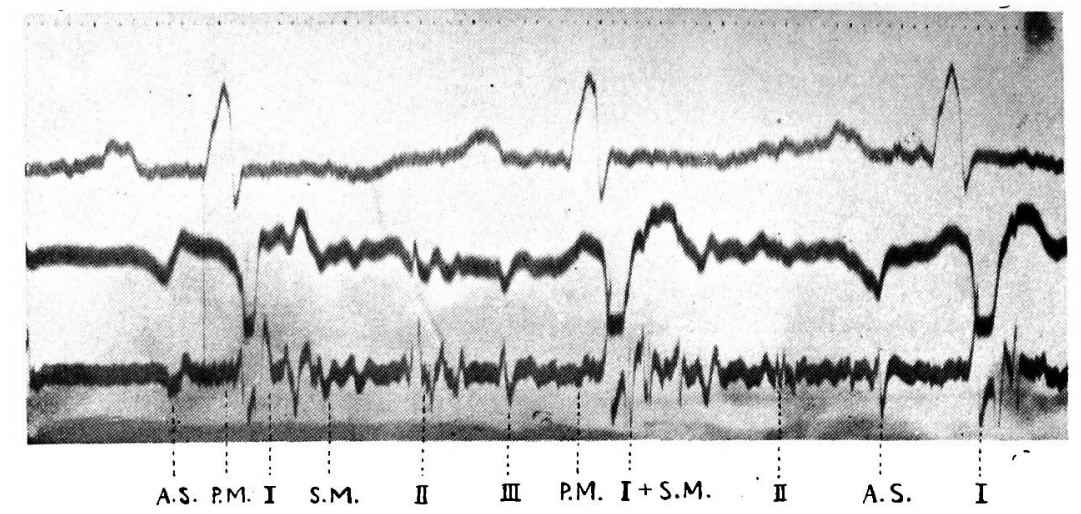

Fig. 5. Tracings from left ventricle near aortic valve.

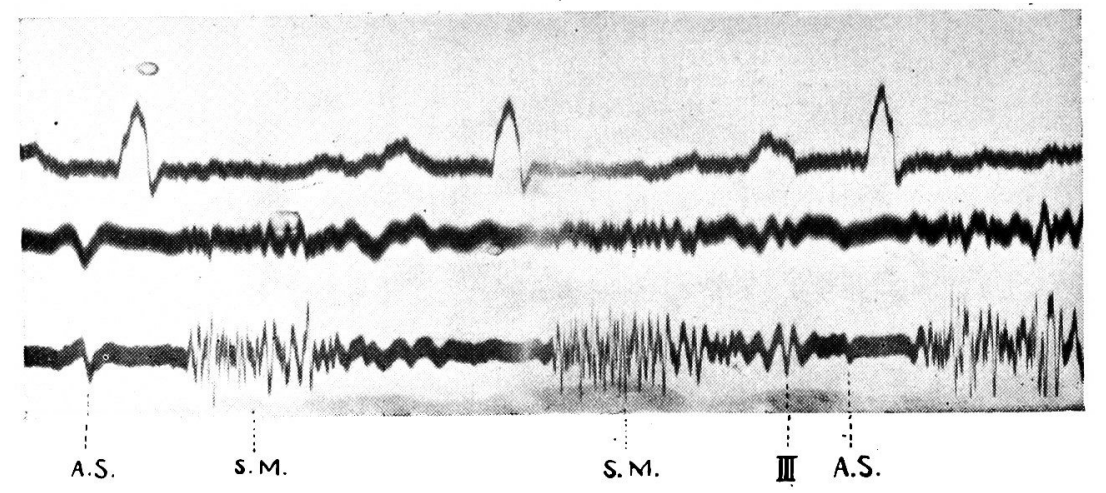

Fig. 6 a

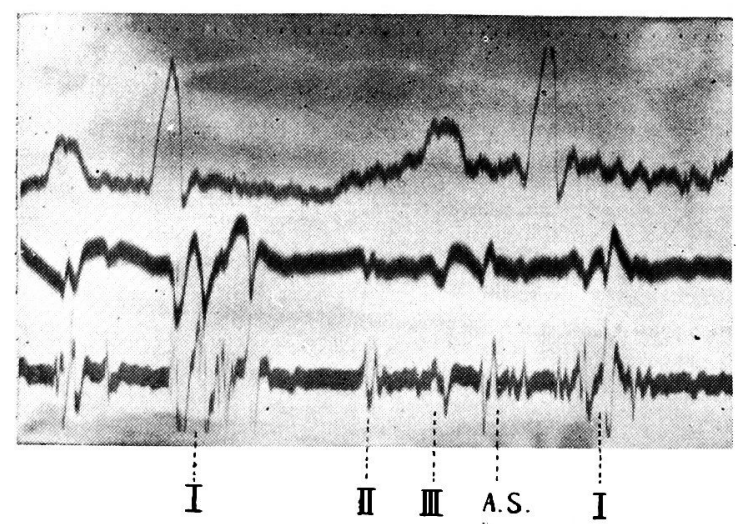

Fig. $6 \mathrm{~b}$ 


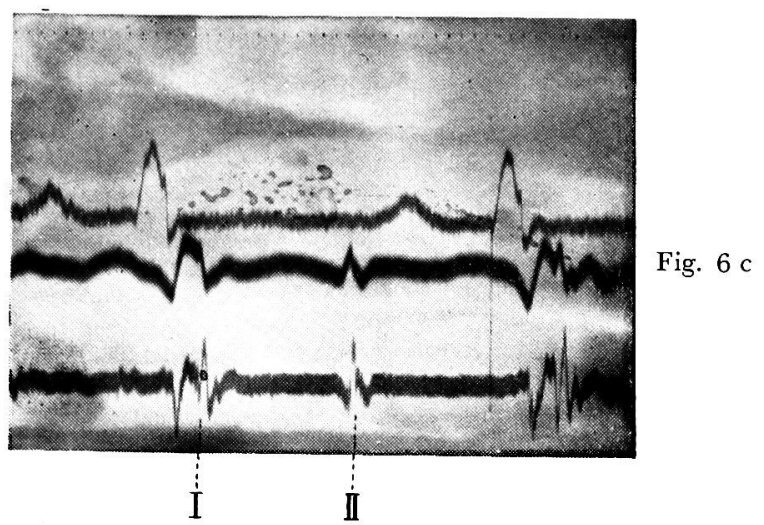

Fig. 6. Tracings from aortic arch and chest wall.

damping effect of heart and arterial walls makes it impossible to hear these sounds upon chest wall in normal healthy case.

3. When the catheter tip is placed in blood stream, chiefly course sounds due to blood whirlpool is recorded, and when the tip is contacted with the inner wall of the heart, chiefly vibrations of a solid structure is recorded. This latter is thought to be one similar to heart sounds obtained from chest wall.

The authors take this opportunity to express their gratitude to Prof. Tasaka for the reviewing of this manuscript.

\section{References}

1) Yamakawa et al., Tohoku J. Exp. Med. 1953, 58, 311.

2) Tomomatsu, Takasaki et al., Nippon Junkankibyo Gaku (The Nippon Journ. of Angiocardiology), 1949, 13, 122.

3) Tomomatsu \& Takasaki, ibid., 1950, 14, 183.

4) Tomomatsu, ibid., 1951, 14, 254. 